\title{
Tim Hein, Understanding SeXual Abuse: A GUIDE FOR MinISTRY LEADERS AND SURVIVORS. DOWNERS GROVE, IL: IVP BOOKS, 2018, 192 PP., ISBN-13: 978-0830841356
}

Carlos Alberto Rosas Jiménez ${ }^{1}$

DOI: 10.5294/PEBI.2019.23.2.7

PARA CITAR ESTA RESEÑA / TO CITE THIS REVIEW / PARA CITAR ESTA RESENHA

Rosas-Jiménez CA. Tim Hein, Understanding Sexual Abuse: A Guide for Ministry Leaders and Survivors. Downers Grove, IL: IVP Books, 2018,192 pp., ISBN-13: 978-0830841356. Pers Bioet. 2019; 23(2): 263-265. DOI: https://doi.org/10.5294/pebi.2019.23.2.7

Understanding Sexual Abuse: A Guide for Ministry Leaders and Survivors es un libro que sorprenderá al lector por varias razones. En primer lugar, es un testimonio real de la vida del autor como víctima de abuso sexual en su niñez por una de las personas más cercanas a su familia. En segundo lugar, no es el típico libro sensacionalista que busca llamar la atención, generar lástima, victimizarse o buscar fondos para alguna organización no gubernamental (ONG) de prevención de abuso sexual; más bien, el autor, con mucha apertura interior, humildad, valentía, así como con un elevado profesionalismo, describe lo profundas que pueden ser las heridas de este tipo de abuso y lo crudo e injusto que es este crimen. En tercer lugar, la manera como el autor se aproxima al tratamiento de un trauma como el abuso sexual permite que el lector se identifique plenamente con él, si ha sido abusado sexualmente, o si no, que aun así pueda tomar muchos elementos para sanar traumas de su propia vida, a pesar de no tratarse de abuso sexual, y sobre cómo acompañar a otras personas que han sufrido este tipo de abuso; he aquí la riqueza de este libro.

Tim Hein es PhD in Ministry del Adelaide College of Divinity, candidato a doctor en la Universidad de Flinders, viceprincipal y director de discipulado del Uniting College for Leadership \& Theology en Australia. Hein es ministro ordenado de la Uniting Church en el mismo país, con una experiencia muy amplia en diferentes ministerios y contextos; además, es chairperson de la Biblioteca Teológica de Adelaida.

El libro está dividido en ocho capítulos antecedidos por una breve introducción en la cual el autor menciona que solo después de 11 años pudo hablar de su experiencia de abuso, y que solo después de 21 años de ocurrido el abuso pudo contárselo a sus papás. Pues bien, a continuación,

1 https://orcid.org/0000-0003-1529-3785. Docente de tiempo completo, Facultad de Teología, UniCervantes, Bogotá, Colombia. carlosalbertorosasj@gmail.com 
iremos, capítulo por capítulo, dejando consignados los elementos que nos parecen más relevantes y profundos en la lectura de esta obra.

El primer capítulo se titula "Un lugar seguro". Se menciona aquí que son pocos los lugares seguros en nuestra sociedad, y que es la familia, por encima de cualquier otra institución, el primer lugar donde ocurre la mayor cantidad de abusos sexuales de niños, niñas y adolescentes. De esta manera, en este capítulo el autor quiere hacer énfasis en la necesidad de lugares seguros para poder hablar del abuso, pues infortunadamente, más de la mitad de los abusos sexuales no son revelados (p. 25) porque las personas abusadas no encuentran el lugar propicio para hablar de ello. Sin embargo, a pesar de la necesidad de que los abusos sean revelados, nunca debemos tratar de manipular o presionar para que se manifieste, cuando la persona esté lista lo compartirá (p. 19).

El segundo capítulo, titulado “ ¿Por qué duele el abuso?”, trata las consecuencias biológicas y psicológicas del abuso sexual. De cómo lo más doloroso de este es darse cuenta de haber sido víctima del grooming, que es la práctica de ir construyendo una relación a través de una atención amical, con el objetivo de bajar la inhibición para lograr la actividad sexual indebida (p. 34). El dolor es muy grande porque el abusador traiciona completamente la confianza que la víctima ha depositado en él o ella. A esto se suman la fragmentación de la identidad, la volatilidad emocional, la disociación, los flashbacks, las pesadillas, el pánico, la ansiedad, la rabia, el miedo, la hipervigilancia y el rechazo o el desorden con la genitalidad.

El tercer capítulo, cuyo título es "Rompiendo el poder de los secretos", ahonda en lo nocivo y perjudicial que es la cultura del secreto, pues obstaculiza la posibilidad de revelación del abuso. El abusador manipula a la víctima y controla la situación con el secreto; y lo peor de todo, como dice Hein, es que a veces se forman en las familias o comunidades círculos de confianza que crean un código de silencio que contiene los oscuros secretos de la familia, y que por mantener el "big family secret" (p. 54) nadie dice nada sobre el abuso.

En el cuarto capítulo, titulado “¿Cómo es la recuperación?”, el autor describe que la recuperación no se da al final de un camino, sino que cada paso dado es parte fundamental de dicha recuperación, en sus palabras: "it's a journey of recovery, not just a journey to recovery” (p. 79). El autor menciona trece pasos para dicha recuperación, pero los sintetiza en tres: la búsqueda de seguridad; el recuerdo y el duelo; y la reconexión con la vida ordinaria (p. 82).

El capítulo cinco versa sobre la "Justicia, la rabia y la pregunta sobre el perdón”. El autor es muy enfático en no insistir en un perdón forzado, pues cualquier trauma se exacerba al realizar intentos de perdonar para olvidar, dado que el perdón obligado no es real, pues toma tiempo perdonar verdaderamente. Las llamadas radicales a perdonar tienen que ser bien enseñadas puesto que, para perdonar, primero hay que condenar (p. 99), y esto muchas veces trae rabia, la cual es normal en un proceso de duelo. Si no se reconoce lo abusivo de los actos cometidos, es muy difícil poder sanar las heridas.

El capítulo sexto hace una pregunta trascendental, “¿Dónde está Dios?”. Este cuestionamiento es la expresión del reclamo más natural frente a la injusticia sufrida por una víctima de abuso sexual. Esta pregunta se expresa en las víctimas en su deseo de volver a nacer 
o incluso en la posibilidad de haber tenido otra vida. El autor no entra en discusiones filosóficas o teológicas para responder esta pregunta, simplemente reconoce que muchas veces esta es fruto de un deseo del ser humano de controlar todo, lo cual es imposible, pues si usted o yo quisiéramos un mundo sin dolor, probablemente no hubiéramos nacido.

El penúltimo capítulo, que se titula "Un Aleluya roto", hace referencia a que el proceso de sanación del abuso sexual es una mezcla constante de alegría-dolor. Lo que más valora el autor sobre cómo fue acompañado en ese proceso es que los que mejor lo acompañaron fueron quienes, a su lado, se sintieron también inútiles y sin poder hacer nada, tal como él se sentía. Es allí, en esa experiencia de impotencia y de paciente espera, sin el afán desmedido de encontrar una solución, donde se logra percibir que sí existe una salida, que la oscuridad y la muerte no tienen la última palabra, sino que existe una luz al final del camino y que se puede alcanzar.

El octavo y último capítulo se titula "Eligiendo vida", pues a pesar de que las consecuencias y las implicaciones de la ruptura van muy lejos, más de lo que estamos preparados para admitir (p. 159), cada paso del proceso de recuperación concluye algo. Por tanto, es importante lanzarse a elegir vida, arriesgarse a seguir viviendo por difícil que sea, a pesar de que el pasado esté siempre tratando de secuestrar el presente (pp. 28, 163). El autor reitera la importancia de sentirse libre de pedir ayuda cuantas veces sea necesario y de abrir el corazón de par en par, pero solo a amigos muy cercanos porque, de lo contrario, se puede hacer un daño peor al compartir este trauma con demasiadas personas. El autor aconseja buscar santuarios físicos y espirituales para sentirse seguros y recobrar la estabilidad, valorar el poder reparador de las lágrimas y tomarse el tiempo con lo sexual, pues incluso las parejas que no son sobrevivientes de abuso sexual experimentan tensiones en esa área (p. 164).

En este punto, es clara la falta de una conclusión general del libro, pues la obra termina con las últimas palabras del octavo capítulo, y deja en el aire el conjunto de toda la reflexión. No obstante, el autor alcanza un equilibrio poco logrado en obras testimoniales de víctimas de abuso. En este caso, además de ser de muy fácil lectura, el libro presenta aspectos tanto superficiales como profundos de la realidad del abuso, y, además de ser un texto basado en un testimonio personal muy abierto, posee un aparato crítico valioso para quien quiera indagar más sobre la realidad del abuso sexual y su terapéutica.

Finalmente, como dijimos al inicio, esta obra es muy valiosa para tomar conciencia acerca de la degradación humana que representa el abuso sexual de niños, niñas y adolescentes, así como para comprender la necesidad de que haya más personas disponibles para prevenirlo y para acompañar a las víctimas. Igualmente, dada la fineza y profundidad con que se manejan los temas, puede servir de herramienta para otras personas que, sin haber sufrido abuso sexual, hayan pasado por otros traumas que también necesitan ser sanados. 